\title{
Augmented Reality Video Games: New Possibilities and Implications for Children and Adolescents
}

\author{
Prithwijit Das, Meng'ou Zhu, Laura McLaughlin, Zaid Bilgrami and Ruth L. Milanaik* \\ Division of Developmental and Behavioral Pediatrics, Steven and Alexandra Cohen Children's Medical \\ Center of New York, Northwell Health System, Lake Success, NY 10042, USA; pdas4@northwell.edu (P.D.); \\ mary.mengou.zhu@gmail.com (M.Z.); mclaughlin.laura@ymail.com (L.M.); zaidbilgrami94@gmail.com (Z.B.) \\ * Correspondence: rmilanai@northwell.edu; Tel.: +1-516-802-6100
}

Academic Editors: Carolina Cruz-Neira, Marcos Fernández Marín and Cristina Portalés Ricart Received: 17 February 2017; Accepted: 19 April 2017; Published: 22 April 2017

\begin{abstract}
In recent years, the video game market has embraced augmented reality video games, a class of video games that is set to grow as gaming technologies develop. Given the widespread use of video games among children and adolescents, the health implications of augmented reality technology must be closely examined. Augmented reality technology shows a potential for the promotion of healthy behaviors and social interaction among children. However, the full immersion and physical movement required in augmented reality video games may also put users at risk for physical and mental harm. Our review article and commentary emphasizes both the benefits and dangers of augmented reality video games for children and adolescents.
\end{abstract}

Keywords: augmented reality; video games; children; adolescents; health; education

\section{Introduction}

The twenty-first century has experienced a digital revolution marked by rapid growth of information and communication technologies. Today's children are growing up in an increasingly interdependent and globalized society, with unprecedented access to information, people, and ideas. Consequently, this has resulted in new opportunities to access media via the Internet and other electronic mediums. The video game industry has demonstrated tremendous growth to become one of the most popular forms of entertainment around the world. Video game development has accelerated in recent years, with the advent of new platforms and dynamic games that are more complex and interactive than their predecessors [1]. Recent advancements in video games have incorporated augmented reality (AR) technology in their design. This technology allows users to interact with synthetic objects, people, and settings that have been overlaid onto real-world environments, augmenting their experiences in these environments with computer-generated imagery and sounds [2]. While applications of AR technology continue to develop, it is important to consider the potential impact that applications of this technology in gaming may have on children and adolescents who play these games. This review focuses on the positive and negative implications of augmented reality video games (ARGs) on children and adolescents, aiming not only to examine their physical, mental, academic, and social ramifications but also to discuss the continued role of parents and pediatricians as ARGs evolve and expand.

\section{History of Augmented Reality Video Games}

The application of AR technology to video games began in 2000 [3]. While traditional (non-augmented reality) video games often place the user in a first-person view of a virtual world [4], ARGs allow users to see and interact with enhanced images of real-world environments [3]. The first 
outdoor ARG with easily portable devices, ARQuake, was developed in 2000 by Bruce Thomas from Wearable Computer Lab [3]. Instead of using a joystick, players were able to walk around and view enhanced images through a gyroscope based on their physical location [3]. Around 2010, ARGs expanded to smartphones [5], and a significant number of smartphone-based ARGs quickly gained popularity around the world. Several famous ARGs, such as Zombies, Run! and DJ Rivals, have been downloaded by more than 500,000 players from the Google Play App Store [6].

In 2016, the release of Pokémon GO by Niantic became a milestone in the history of ARGs. The term Pokémon refers to "pocket monsters" from a popular Japanese anime and card game. The Pokémon franchise initially consisted of traditional arcade and video games, played on devices such as the Game Boy. However, the game has since expanded into a mobile-based AR experience. While Pokémon-themed traditional video games featured digital battles between Pokémon, Pokémon GO used AR technology to merge the "Pokémon world" with reality. Players use their smartphones to detect, capture, and collect Pokémon from real-life locations. Players can also collect digital in-game resources at real world locations called PokéStops or battle other players with their digital Pokémon at PokéGyms. The groundbreaking gaming experience, along with the popularity and nostalgia associated with the anime series, turned Pokémon GO into a worldwide phenomenon. Released on July 6, this game was downloaded 500 million times by September 15, with the average number of daily active users reaching 20 million [7]. An online poll conducted by Forbes News indicated that $22 \%$ of Pokémon GO players were between the ages of 13 and 17 years old, while $46 \%$ were between 18 and 29 [8]. Updates to Pokémon GO continue to be made, and additional features are expected to be incorporated as the game draws in more players [9].

\section{Positive Implications of ARGs}

\subsection{Increased Socialization}

Although most traditional video games can be played solo, many incorporate strong social components into the gameplay experience, either directly or indirectly. A 2008 Pew survey of adolescents in the United States found that the majority of teenagers ( $76 \%$ ) play video games with others, either online or in person. Furthermore, $65 \%$ of teens play traditional video games with others who are in the same room. Only $24 \%$ of adolescents report exclusively playing video games alone [10]. Indirectly, video games may serve as a source of shared interest amongst players, sparking conversations and facilitating friendships.

In comparison to traditional video games, ARGs may be inherently more social. Players are required to interact with the surroundings and often encounter friends and fellow players. For example, Pokémon GO and other ARGs have many features that promote social interaction between players. PokéStops and PokéGyms function as meeting places where players can congregate to gather resources. Pokémon GO players can also join one of three teams once they reach a certain level. Players on the same team are encouraged to work together to strengthen their Pokémon and gain or maintain control of PokéGyms [11]. The team feature further increases the social component of Pokémon GO because players must work with teammates in order to advance. In this way, Pokémon GO can function like multiplayer online games that have "guilds" or teams that facilitate community interaction. Previous research has documented the social benefits provided by such online interactions. These games create online "third places" where informal conversations and relationships can develop [12]. Gentile et al. [13] conducted a series of correlational, longitudinal, and experimental studies that demonstrated predictive associations between playing video games that require cooperation among players and prosocial behaviors. A 2015 Pew survey highlighted how evolving electronic gaming spaces can create increased opportunities for teens to build new friendships. Fifty-seven percent of all teens surveyed reported having made new friends online through networked video games and social media applications such as Facebook and Instagram, representing the most common digital venues for establishing new connections [14]. Most recently, the 2016 Essential Facts 
about the Computer and Video Game Industry reported that $53 \%$ of the most frequent game players surveyed felt that video games helped them connect with friends [15]. Similarly, the true value of Pokémon GO and other ARGs could be in the broad connections made between individuals. While such tentative relationships might not be as substantial as those of closer, more intimate friendships, they do not appear to damage the social fabric and may hold the potential to enhance it.

Numerous anecdotal reports emerged after Pokémon GO's release about the social benefits that resulted from playing the game. Children with autism had newfound courage and confidence to explore local areas and interact with their peers. It is thought that the repetitive tasks of collecting Pokémon and improving their skill level might appeal especially to these children and provide them with a common interest with their peers [16]. Simple questions about the game can facilitate otherwise difficult dialogue between children with autism and other children playing the game. In some cases, Pokémon GO has also been reported to be beneficial for those suffering from depression, motivating people to get out of the house and get exercise when they otherwise would stay at home [17].

The social benefits of playing ARGs are not limited to between peers-parents and children can also play together. In the case of Pokémon GO, parents and children can embark on outdoor adventures, hunting for Pokémon and discovering local PokéStops together. Children can assume the role of teacher and explain how to play the game to their less technologically adept parents. These games provide parents with an opportunity to bond with their children over a shared interest. In short, the interactive nature of Pokémon GO and other ARGs can facilitate many positive social interactions between children and their peers as well as older family members.

\subsection{Exergaming}

A large body of research has established the association between sedentary video gameplay and health risks such as poor cardiometabolic outcomes (e.g., high body mass index, high adiposity, and weight gain) [18]. Given their integration of physical movement, ARGs can be categorized as active video games (AVG), which may mitigate health risks associated with sedentary gameplay and possibly improve the health of gamers [19].

A study of 12 Japanese adults demonstrated that 22 of the 66 activities that can be played in two popular AVGs, Wii Sports, and Wii Fit Plus, could be considered moderate intensity exercises based on energy expenditure levels [20]. Lanningham-Foster et al. [21] reported similar results in their study of 23 children 10-13 years old. Energy expenditure levels were assessed while participants played two AVGs, Dance Dance Revolution (DDR) and Wii-Sports Boxing, and were compared with energy expenditure levels from walking on a treadmill at three different speeds. Playing DDR and walking on the treadmill at the highest tested speed resulted in similar energy expenditure levels. The active games also showed significant elevations in expired ventilation $\left(\mathrm{V}_{\mathrm{O} 2}\right)$ and heart rate compared with these measures for children watching television at rest.

Findings such as these demonstrate the utility of AVGs as effective interventions for obesity prevention [21]. Like the AVGs, ARGs allow gamers to replace sedentary screen time with active gameplay and show promising potential for promoting health. Although research exploring the effects of ARGs on physical activity is limited, a recent study by Howe et al. [22] suggests that changes in physical activity as a result of playing Pokémon GO are moderate and not sustained. However, these findings have yet to be corroborated by other studies and are specific to Pokémon GO. Nevertheless, this study suggests a potential opportunity for ARG developers to create ARGs that promote health benefits.

\subsection{Promotion of Healthy Behaviors}

ARGs can also be used to influence child and adolescent behavior. Currently, in Japan, Pokémon GO is partnered with McDonald's such that all McDonald's restaurants are designated PokéStops or PokéGyms, thereby attracting players to the restaurant and demonstrating the potential influence that such a game has on consumer behavior [23]. Pokémon GO and other ARGs could be 
used to promote healthy behaviors instead of encouraging unhealthy ones, such as the consumption of nutrient-poor, calorically dense fast food sold at McDonald's. Instead, farmer's markets or outdoor exercise equipment locations can be made into ARG points of attraction. Young players could be encouraged to frequent these and other locations and thus might be more likely to purchase healthy fruits and vegetables or partake in casual physical activity. Advancement in ARGs can feasibly be contingent on participation in such healthy behaviors. For example, players could only level up if they walk a certain distance or burn a certain number of calories while playing. ARGs can be used as extrinsic motivation to encourage children to engage in activities or eat foods that are beneficial to their health.

Furthermore, ARGs can also be used to improve children's emotional health. Pokémon GO has been used at pediatric hospitals as a tool to get sick children out of bed and interact with other patients and hospital staff [24]. Although the extra traffic caused by Pokémon GO attractions near hospitals can be potentially problematic, the emotional benefits conferred to pediatric patients may outweigh the inconvenience. Less substantially, ARGs can also be used as distractions during medical procedures such as vaccinations or blood withdrawals. If designed effectively, ARGs could be a powerful tool to reduce childhood stress and anxiety surrounding medical procedures, both minor and more significant.

\subsection{Impacts on Education and Teaching Practices}

ARGs present a number of unique possibilities for teaching practices and learning opportunities in educational settings. Educational researchers and teaching staff are gradually realizing many of the useful affordances that ARGs offer in instructional environments. Johnson et al. [25] demonstrated how ARGs using marker technology can create three-dimensional settings from flat maps and game boards, which can in turn be applied to various school subjects such as archaeology, anthropology, and geography. Schrier [26] designed and tested an ARG that could help teach history. It allows players to interact with virtual historic items and figures and learn more about historical events depending on their location. Klopfer et al. [27] developed an ARG that could simulate situated active learning by providing students with portable handheld computers that enhance their experiences conducting investigations, gathering data, and creating context-specific solutions to challenges. ARGs can be used to enhance student participation, educational outcomes, and excitement for the learning process.

Previous studies have also looked at the use of ARGs in learning environments outside of school such as zoos and museums [28]. Gamification or the incorporation of game elements to non-game situations can enhance learning experiences in these settings [29,30]. Students can participate in fun activities such as treasure hunts on mobile devices during museum visits and actively gather information on topics while making observations [31]. Following these visits, they can reflect on the concepts they learned, connect it back to lessons taught in the classroom, and share their knowledge with their peers.

ARGs offer a number of advantages to the present generation of learners. For many individuals, games give rise to informal multi-sensory learning environments that necessitate mental and physical investment, creating more immersive experiences. In many instances, games put forth challenges that require players to develop problem-solving strategies, while providing context, feedback, and assessment. Whole digital learning communities have developed around discussions of games and strategies, allowing those involved to have the opportunity to engage in meta-cognition [32]. Ultimately, players could transfer knowledge learned playing ARGs to other situations.

\section{Negative Consequences of ARGs}

\subsection{Physical Safety}

Video game-related injuries have been widely observed since the advent of video games $[33,34]$. As the video game market shifted from exclusively controller-based games to include motion-tracking technologies, physical risks of gameplay increased, with the potential for more traumatic injuries to 
the entire body [33]. ARGs may increase the risk for injury even beyond that of motion-tracking games. Given the popularity of ARGs, this risk is especially concerning.

Research on physical injuries resulting from ARGs is limited. However, several reports of accidents and injuries from playing Pokémon GO emerged soon after the game's release [33,35]. Gamers sustained fractures, bruises, sprains, and motor vehicle accidents that were largely attributed to gamers' inattentiveness as a result of deep fixation on the game [35]. Given the inherently immersive and absorbing nature of ARGs, the dangers of playing Pokémon GO are likely to be similar to future ARGs. Research has shown that children engage in unsafe pedestrian behaviors when distracted by cell phones [36], and ARGs provide another enticing distraction that may put gamers at risk of injury and motor vehicle accidents, dangers that are largely preventable. While rates of injuries that result specifically from playing ARGs have not been studied, it is known that unintentional injuries are the leading cause of death among 5-44 year olds, which captures the majority of Pokémon GO players [37]. Parents, researchers, and physicians must therefore carefully assess new ARGs that may exacerbate the risk of preventable accidents.

While several video games enable online social interaction, some ARGs may encourage in-person interaction with other gamers, which poses clear risks to children. In an alarming case following the release of Pokémon GO, armed robbers used a geolocation function of the game to lure victims to an isolated location and rob them [38]. Unfortunately, these technologies may also be used by sexual predators seeking young victims. Online identities are easily fabricated and can pose significant risks to the wellbeing and safety of children and adolescents. Research must keep pace with the rapid development of video game technologies in order to inform parents of the risks that ARGs pose to children and adolescents.

\subsection{Mental Safety}

ARGs may also carry potentially detrimental consequences for mental and behavioral health. With the rapid growth and development of the Internet and gaming industry, "Internet gaming disorder" has become recognized in the Diagnostic and Statistical Manual of Mental Disorders [39]. The American Society of Addiction Medicine defines addiction as "a primary, chronic disease of brain reward, motivation, memory, and related circuitry" [40]. A number of previous studies have documented the addictive nature of modern online technologies such as video games. Van Rooij et al. [41] successfully utilized a data-driven approach to identify addicted online video gamers. The study not only offers a prevalence estimate for video game addiction but also provides some of the first longitudinal data regarding the development of this addiction over time. However, it primarily uses self-reported data, which can potentially contain a degree of bias. Results should therefore be evaluated and extrapolated by taking this risk into consideration. Andreassen et al. [42] highlighted significant positive correlations between symptoms of addictive technology use and mental disorder symptoms. This study builds upon previous empirical investigations, which utilized small and non-representative samples, by using a much larger and broader sample, thereby increasing the statistical reliability of the identified associations. Yet, its use of a web-based convenience sampling methodology may impact representativeness and limit the extension of the study's findings to other populations. Nevertheless, such investigations draw attention to the prevalence of video game addiction and lend evidence to the existence of negative mental and behavioral conditions associated with video game addiction. In a study conducted by Mentzoni et al. [43] associations were found between problematic video game usage, defined by respondents endorsing at least four out of seven items listed in the Gaming Addiction Scale for Adolescents, and increased symptoms of depression, anxiety, and stress. Although it has a relatively low response rate, the study's cross-sectional design and usage of a validated game addiction scale lend credence to its conclusions. For affected players, these symptoms may result in adverse effects in other aspects of their lives including their academic performance and dietary choices [35]. In other cases, adolescents with Internet gaming disorder 
could be at risk for other types of addictive behaviors due to a heightened predisposition to act impulsively [41].

Gamers may be at increased risk of developing addiction to games that utilize AR elements and experience these effects. Non-ARGs as well as ARGs such as Pokémon GO may also appeal to players due to their roles as maladaptive coping strategies. These games may offer players a form of avoidance and escape from underlying conflicts in their lives, resulting in heightened distress, negative emotions, burnout, and failure to achieve goals and uphold responsibilities [44,45]. These outcomes are also associated with depression, anxiety, and stress.

In some cases, exposure and participation in violent games may lead to increasingly aggressive behaviors and diminished sensitivity to violence. This aggression can manifest in certain instances as cyberbullying, where individuals use electronic means to intentionally harm others [46]. In the context of ARGs, platforms such as chat rooms and discussion forums can serve as vehicles for cyberbullies to harass other players [47]. Bullying of this nature has been found to be associated with symptoms of depression, hyperactivity, conduct problems, and suicidal ideation [47,48].

Parental monitoring and mediation of children's video game use may protect against these consequences. By talking with children about the content of these games and restricting the amount of time spent playing, parents can appropriately offer guidance and support to help their children achieve more positive outcomes. Increasing parental involvement in reducing screen time and violence exposure can positively influence the social, emotional, and academic performance of children [49].

\subsection{Ethical Issues of ARG Usage}

In addition to physical and mental safety risks, ARG use among children and adolescents presents important ethical issues, particularly with regard to privacy and persuasion. ARGs have the capability - and the incentive- to record massive amounts of user information, such as a user's current location, patterns in his or her daily travel, and his or her purchasing choices. ARGs can then use this information to manipulate user behaviors by rewarding and punishing certain actions [50]. For example, a child playing Pokémon GO could be located using the geolocation feature and might be enticed to a nearby fast food restaurant where he or she could obtain an in-game reward.

Several qualities of ARGs, such as their persistence, ability to constantly surveil users, and manipulate user emotions, enable them to effectively influence user actions [50]. Minors are a particularly vulnerable population to the powerful, data-driven persuasion techniques. As seen with Pokémon GO, children may be encouraged to make unhealthy choices and their location data can be used to harm them [23,38]. As stated by other researchers, ARG developers must consider these and other ethical values when designing future games [51].

\section{Continued Role of Parents and Pediatricians}

With the evolving landscape of digital technologies, advanced software and devices have grown in popularity and proliferated significantly across the globe. The digital era has introduced a new world where individuals possess digital identities and rely greatly on technology everyday [52]. Children and adolescents, in particular, are growing up in media-saturated environments and are using an ever-increasing variety of technologies daily [53]. Technology has profoundly transformed the lives of youth; thus, pediatricians must be prepared to evaluate their patients on health-related issues associated with their technology exposure and usage. ARGs are a relatively novel application and their long-term effects on physical, emotional, cognitive, and social development are unknown. While further research into the health and developmental impacts of ARGs and other AR applications is needed, pediatricians should monitor the literature for findings about the potential physical safety and mental health risks of AR technology. Pediatricians should be aware of their patients' level of participation in these games and be open to having deeper discussions with parents regarding how these games influence pediatric health. Parents themselves are encouraged to open dialogue with 
their children and establish rules regarding digital device usage [35]. Parents are also encouraged to participate in ARGs with their children, as they may facilitate bonding.

\section{Conclusions}

The rapid advances made in the contemporary digital era underscore the tremendous ways that technology has permeated our cultures and society. This paper highlights the potential implications of ARGs on the lives of children and adolescents. The blending of virtual and real-world elements creates exciting new possibilities not just for immersive gameplay, but also for increased socialization and exercise. The heavily interactive features of AR also provide a powerful tool for teachers as well as students seeking motivation throughout the learning process. However, this paper also reported a number of potential risks to its use by children and adolescents. Incidents of injury to players of ARGs have been documented, resulting from increased inattentiveness. Real-time location tracking functions also increase the threat of physical harm. Additionally, mental health and safety could be in danger if gameplay becomes an addiction or players become targets for cyberbullying. It is important for pediatricians to be aware of the health risks associated with the growing presence of these technologies in the lives of pediatric patients. Parents should also play a large role in regulating their children's usage of such technologies. With structure and supervision, children and adolescents may enjoy the benefits of AR technology applications like ARGs. Further studies should continue to explore the consequences and opportunities afforded by AR.

Author Contributions: All authors have contributed substantially to the conception, writing, and revision of this manuscript.

Conflicts of Interest: The authors declare no conflict of interest.

\section{References}

1. Egenfeldt-Nielsen, S.; Smith, J.H.; Tosca, S.P. Understanding Video Games: The Essential Introduction; Routledge: New York, NY, USA, 2008; pp. 2-17.

2. Dunleavy, M.; Dede, C.; Mitchell, R. Affordances and Limitations of Immersive Participatory Augmented Reality Simulations for Teaching and Learning. J. Sci. Ed. Technol. 2009, 18, 7-22. [CrossRef]

3. Piekarski, W.; Thomas, B. ARQuake: The outdoor augmented reality gaming system. Commun. ACM 2002, 45, 36-38. [CrossRef]

4. Klinker, G.J.; Ahlers, K.H.; Breen, D.E.; Chevalier, P.; Crampton, C.; Greer, D.S.; Koller, D.; Kramer, A.; Rose, E.; Tuceryan, M.; et al. Confuence of computer vision and interactive graphics for augmented reality. PRESENCE Teleoper. Virtual Environ. 1997, 6, 433-451. [CrossRef]

5. Wu, H.; Wen-Yu, S.; Chang, H.; Liang, J. Current status, opportunities, and challenges of augmented reality in education. Comput. Ed. 2013, 62, 41-49. [CrossRef]

6. Eishita, F.; Stanley, K. Analyzing play experience sensitivity to input sensor noise in outdoor augmented reality smartphone games. In Proceedings of the 2015 British HCI Conference, Lincoln, Lincolnshire, UK, 56-64 July 2015.

7. Hot Game: Amazing Pokémon Go Statistics. Available online: http://expandedramblings.com/index.php/ pokemon-go-statistics/ (accessed on 16 February 2016).

8. More Women Than Men Are Playing Pokémon GO'-By a Lot. Available online: http://www.forbes.com/ sites/ryanmac/2016/07/26/more-women-than-men-are-playing-pokemon-go-by-a-lot/\#217b84384f16 (accessed on 16 February 2017).

9. Here's How to Best Prepare for Pokémon GO's Gen 2 Update. Available online: http: //www.forbes.com/sites/insertcoin/2017/02/16/heres-how-to-best-prepare-for-pokemon-gosgen-2-update/\#40cbd8fd2d86 (accessed on 16 February 2017).

10. Lenhart, A.; Kahne, J.; Middaugh, E.; MacGill, A.; Evans, C.; Vitak, J. Teens, Video Games and Civics; Pew Research Center, 2008. Available online: http://www.pewinternet.org/2008/09/16/teens-videogames-and-civics/ (accessed on 14 February 2017). 
11. 'Pokémon GO-Teams and Gyms'. Niantic, Inc. Available online: http://www.pokemongo.com/en-us/ teams-gyms / (accessed on 14 February 2017).

12. Steinkuehler, C.A.; Williams, D. Where Everybody Knows Your (Screen) Name: Online Games as "Third Places". J. Comput. Med. Commun. 2006, 11, 885-909. [CrossRef]

13. Gentile, D.A.; Anderson, C.A.; Yukawa, S.; Ihori, N.; Saleem, M.; Ming, L.K.; Shibuya, A.; Liau, A.K.; Khoo, A.; Bushman, B.J.; et al. The effects of prosocial video games on prosocial behaviors: International evidence from correlational, longitudinal, and experimental studies. Personal. Soc. Psychol. Bull. 2009, 35, 752-763. [CrossRef] [PubMed]

14. Lenhart, A.; Smith, A.; Anderson, M.; Duggan, M.; Perrin, A. Teens, Technology \& Friendships. Pew Research Center, 2015. Available online: http:/ / www.pewinternet.org/2015/08/06/teens-technologyand-friendships / (accessed on 2 April 2017).

15. Entertainment Software Association. Essential Facts about the Computer and Video Game Industry. 2012. Available online: http:/ / essentialfacts.theesa.com/Essential-Facts-2016.pdf (accessed on 3 April 2017).

16. How Pokémon Go Might Actually Be Helping Kids with Autism. Available online: http://nymag.com/ scienceofus / 2016/07/why-pokmon-go-might-actually-be-helping-kids-with-autism.html (accessed on 14 February 2017).

17. The Surprising Health Benefit to Playing 'Pokémon Go' That All the Haters Should Hear. Available online: http://mic.com/articles/148322/pokemon-go-has-mental-health-benefits\#.EQ6W09ah9 (accessed on 14 February 2017).

18. Fletcher, E.; Leech, R.; McNaughton, S.A.; Dunstan, D.W.; Lacy, K.E.; Salmon, J. Is the relationship between sedentary behaviour and cardiometabolic health in adolescents independent of dietary intake? A systematic review. Obes. Rev. 2015, 16, 795-805. [CrossRef] [PubMed]

19. Chen, J.L.; Wilkosz, M.E. Efficacy of technology-based interventions for obesity prevention in adolescents: A systematic review. Adolesc. Health Med. Ther. 2014, 5, 159-170. [CrossRef] [PubMed]

20. Miyachi, M.; Yamamoto, K.; Ohkawara, K.; Tanaka, S. METs in adults while playing active video games: A metabolic chamber study. Med. Sci. Sports Exerc. 2010, 42, 1149-1153. [CrossRef] [PubMed]

21. Lanningham-Foster, L.; Jensen, T.B.; Randal, F.C.; Redmond, A.B.; Walker, B.A.; Heinz, D.; Levine, J.A. Energy Expenditure of Sedentary Screen Time Compared With Active Screen Time for Children. Pediatrics 2006, 118, 1831-1835. [CrossRef] [PubMed]

22. Howe, K.B.; Suharlim, C.; Ueda, P.; Howe, D.; Kawachi, I.; Rimm, E.B. Gotta catch'em all! Pokémon GO and physical activity among young adults: Difference in differences study. BMJ 2016, 355, i6270. [CrossRef] [PubMed]

23. Marshall, W. Pokémon GO Is Taking over Every McDonald's in Japan. The Vice Channels. 2016. Available online: http://munchies.vice.com/en/articles/pokemon-go-is-taking-over-every-mcdonalds-in-japan (accessed on 14 February 2017).

24. Bowerman, M. Children's Hospital Using 'Pokémon Go' to Get Patients out of Bed. USA Today. 2016. Available online: http://www.usatoday.com/story/tech/nation-now/2016/07/15/motts-childrenshospital-michigan-pokemon-go-get-children-interacting-rooms-technology/87086698/ (accessed on 14 February 2017).

25. Johnson, L.; Levine, A.; Smith, R.; Stone, S. Simple augmented reality. In The 2010 Horizon Report; The New Media Consortium: Austin, TX, USA, 2010; pp. 21-24. Available online: http://www.nmc.org/pdf/2010Horizon-Report.pdf (accessed on 2 April 2017).

26. Schrier, K.L. Revolutionizing History Education: Using Augmented Reality Games to Teach Histories. Doctoral Dissertation, Massachusetts Institute of Technology, Cambridge, MA, USA, 2005. Available online: http:/ / cmsw.mit.edu/wp/wp-content/uploads/2016/10/146381100-Karen-Schrier-RevolutionizingHistory-Education-Using-Augmented-Reality-Games-to-Teach-Histories.pdf (accessed on 2 April 2017).

27. Klopfer, E.; Squire, K. Environmental detectives-The development of an augmented reality platform for environmental simulations. Ed. Technol. Res. Dev. 2008, 56, 203-228. [CrossRef]

28. Vavoula, G.; Sharples, M.; Rudman, P.; Meek, J.; Lonsdale, P. Myartspace: Design and evaluation of support for learning with multimedia phones between classrooms and museums. Comput. Ed. 2009, 53, 286-299. [CrossRef] 
29. Yoon, S.; Elinich, K.; Wang, J.; Steinmeier, C.; Tucker, S. Using augmented reality and knowledge-building scaffolds to improve learning in a science museum. Int. J. Comput. Support. Collab. Learn. 2012, 7, 519-541. [CrossRef]

30. Lu, Y.; Chao, J.T.; Parker, K. HUNT: Scavenger hunt with augmented reality. Interdiscip. J. Inf. Knowl. Manag. 2015, 10, 21-35.

31. Kohen-Vacs, D.; Ronen, M.; Cohen, S. Mobile treasure hunt games for outdoor learning. IEEE Bull. Tech. Comm. Learn. Technol. 2012, 14, 24-26.

32. Oblinger, D. The Next Generation of Educational Engagement. J. Int. Media Ed. 2004, 8, 1-18. [CrossRef]

33. Pourmand, A.; Lombardi, K.; Kuhl, E.; O'Connell, F. Videogame-Related Illness and Injury: A Review of the Literature and Predictions for Pokémon GO! Games Health J. 2017, 6, 9-18. [CrossRef] [PubMed]

34. Jalink, M.B.; Heineman, E.; Pierie, J.P.; ten Cate Hoedemaker, H.O. Nintendo related injuries and other problems: Review. BMJ 2014, 349, g7267. [CrossRef] [PubMed]

35. Serino, M.; Cordrey, K.; McLaughlin, L.; Milanaik, R.L. Pokémon Go and augmented virtual reality games: A cautionary commentary for parents and pediatricians. Curr. Opin. Pediatr. 2016, 28, 673-677. [CrossRef] [PubMed]

36. Stavrinos, D.; Byington, K.W.; Schwebel, D.C. Effect of cell phone distraction on pediatric pedestrian injury risk. Pediatrics 2009, 123, e179-e185. [CrossRef] [PubMed]

37. Centers for Disease Control and Prevention. Web-Based Injury Statistics Query and Reporting System (WISQARS). 2011. Available online: http://www.cdc.gov/injury/wisqars/index.html (accessed on 31 March 2017).

38. Yuhuas, A. Pokemon Go: Armed Robbers Use Mobile Game to lure Players into Trap. The Guardian. 11 July 2016. Available online: http://www.theguardian.com/technology/2016/jul/10/pokemon-goarmed-robbers-dead-bdy (accessed on 15 February 2017).

39. Diagnostic and Statistical Manual of Mental Disorders. In American Psychiatric Association, 5th ed.; American Psychiatric Publishing: Arlington, VA, USA, 2013; Available online: http:/ / psychiatry.org/psychiatrists / practice/dsm (accessed on 12 February 2017).

40. American Society of Addiction Medicine. Public Policy Statement: Definition of Addiction. 2011. Available online: http:/ / www.asam.org/quality-practice/definition-of-addiction (accessed on 10 February 2017).

41. Van Rooij, A.J.; Schoenmakers, T.M.; Vermulst, A.A.; Van Den Eijnden, R.J.; Van De Mheen, D. Online video game addiction: Identification of addicted adolescent gamers. Addiction 2011, 106, 205-212. [CrossRef] [PubMed]

42. Andreassen, C.S.; Billieux, J.; Griffiths, M.D.; Kuss, D.J.; Demetrovics, Z.; Mazzoni, E.; Pallesen, S. The relationship between addictive use of social media and video games and symptoms of psychiatric disorders: A large-scale cross-sectional study. Psychol. Addict. Behav. 2016, 30, 252-262. [CrossRef] [PubMed]

43. Mentzoni, R.A.; Brunborg, G.S.; Molde, H.; Myrseth, H.; Skouverøe, K.J.; Hetland, J.; Pallesen, S. Problematic video game use: Estimated prevalence and associations with mental and physical health. Cyberpsychol. Behav. Soc. Netw. 2011, 14, 591-596. [CrossRef] [PubMed]

44. Loton, D.; Borkoles, E.; Lubman, D.; Polman, R. Video game addiction, engagement and symptoms of stress, depression and anxiety: The mediating role of coping. Int. J. Ment. Health Addict. 2016, 14, 565-578. [CrossRef]

45. Tejeiro, R.; Gómez-Vallecillo, J.; Pelegrina, M.; Wallace, A.; Emberley, E. Risk factors associated with the abuse of video games in adolescents. Psychology 2012, 3, 310-314. [CrossRef]

46. Price, M.; Dalgleish, J. Cyberbullyingxperiences, impacts and coping strategies as described by Australian young people. Youth Stud. Aust. 2010, 29, 51-59.

47. Bailin, A.; Milanaik, R.; Adesman, A. Health implications of new age technologies for adolescents review of the research. Curr. Opin. Pediatr. 2014, 26, 605-619. [CrossRef] [PubMed]

48. Sourander, A.; Klomek, A.B.; Ikonen, M.; Lindroos, J.; Luntamo, T.; Koskelainen, M.; Ristkari, T.; Helenius, H. Psychosocial risk factors associated with cyberbullying among adolescents population-based study. Arch. Gen. Psychiatry 2010, 67, 720-728. [CrossRef] [PubMed]

49. Gentile, D.A.; Reimer, R.A.; Nathanson, A.I.; Walsh, D.A.; Eisenmann, J.C. Protective effects of parental monitoring of children's media use prospective study. JAMA Pediatr. 2014, 168, 479-484. [CrossRef] [PubMed] 
50. Pase, S. Ethical Considerations in Augmented Reality Applications. Proceedings of the 2012 EEE International Conference on e-Learning, e-Business, Enterprise Information Systems, and e-Government. 2012. Available online: http:/ / weblidi.info.unlp.edu.ar/worldcomp2012-mirror/p2012/EEE6059.pdf (accessed on 31 March 2017).

51. Friedman, B.; Kahn, P.H., Jr. New Directions Value-Sensitive Design Approach to Augmented Reality. Proceedings of the DARE 2000 on Designing Augmented Reality Environments. 2000. Available online: http: / / dl.acm.org/citation.cfm?id=354694 (accessed on 31 March 2017).

52. Palfrey, J.G.; Gasser, U. Born Digital: Understanding The First Generation of Digital Natives; Basic Books: New York, NY, USA, 2008; pp. 2-17.

53. Vandewater, E.A.; Rideout, V.J.; Wartella, E.A.; Huang, X.; Lee, J.H.; Shim, M. Digital Childhood: Electronic Media and Technology Use Among Infants, Toddlers, and Preschoolers. Pediatrics 2007, 119, $1006-1015$. [CrossRef] [PubMed]

(c) 2017 by the authors. Licensee MDPI, Basel, Switzerland. This article is an open access article distributed under the terms and conditions of the Creative Commons Attribution (CC BY) license (http:/ / creativecommons.org/licenses/by/4.0/). 